\title{
The solution structure of the soluble form of the lipid-modified azurin from Neisseria gonorrhoeae, the electron donor of cytochrome $c$ peroxidase
}

\author{
Cláudia S. Nóbrega a ${ }^{a}$, Ivo H. Saraiva ${ }^{b}$, Cíntia Carreira ${ }^{a}$, Bart Devreese ${ }^{c}$, \\ Manolis Matzapetakis ${ }^{\mathrm{b}}$, Sofia R. Pauleta ${ }^{\mathrm{a}, *}$ \\ a UCIBIO, REQUIMTE, Departamento de Química, Faculdade de Ciências e Tecnologia, Universidade Nova de Lisboa, Campus da Caparica, 2829-516 Caparica, Portugal \\ b Instituto de Tecnologia Química e Biológica António Xavier, Universidade Nova de Lisboa, Av. da República, 2780-157 Oeiras, Portugal \\ c Laboratory of Protein Biochemistry and Biomolecular Engineering, Ghent University, K.L. Ledeganckstraat 35, B-9000 Ghent, Belgium
}

\section{A R T I C L E I N F O}

Article history:

Received 27 July 2015

Received in revised form 25 October 2015

Accepted 13 November 2015

Available online 14 November 2015

\section{Keywords:}

Neisseria

Copper protein

Azurin

Laz

Cytochrome $c$ peroxidase

Solution NMR structure

\begin{abstract}
A B S T R A C T
Neisseria gonorrhoeae colonizes the genitourinary track, and in these environments, especially in the female host, the bacteria are subjected to low levels of oxygen, and reactive oxygen and nitrosyl species. Here, the biochemical characterization of $N$. gonorrhoeae Laz is presented, as well as, the solution structure of its soluble domain determined by NMR. N. gonorrhoeae Laz is a type 1 copper protein of the azurin-family based on its spectroscopic properties and structure, with a redox potential of $277 \pm 5 \mathrm{mV}$, at pH 7.0, that behaves as a monomer in solution. The globular Laz soluble domain adopts the Greek-key motif, with the copper center located at one end of the $\beta$-barrel coordinated by Gly48, His49, Cys113, His118 and Met122, in a distorted trigonal geometry. The edge of the His118 imidazole ring is water exposed, in a surface that is proposed to be involved in the interaction with its redox partners. The heterologously expressed Laz was shown to be a competent electron donor to $N$. gonorrhoeae cytochrome $c$ peroxidase. This is an evidence for its involvement in the mechanism of protection against hydrogen peroxide generated by neighboring lactobacilli in the host environment.
\end{abstract}

(C) 2015 Elsevier B.V. All rights reserved.

\section{Introduction}

During infection, pathogenic microorganisms are frequently exposed to oxidative stress due to reactive oxygen species (ROS) generated by host defense mechanisms. Some of the most common ROS found in biological systems include superoxide anion $\left(\mathrm{O}_{2}^{-}\right)$, hydrogen peroxide $\left(\mathrm{H}_{2} \mathrm{O}_{2}\right)$ and hydroxyl radical (HO) [1]. However, there are other sources of ROS, such as the bacteria's own metabolic process, exposure to factors within host environment, such as metal ions, or commensal organisms that generate oxidants. Pathogenic bacteria from the species Neisseria gonorrhoeae and Neisseria meningitidis, that cause gonorrhea and meningitis, respectively, are constantly exposed to ROS from these various sources and, therefore, have developed numerous defense mechanisms to cope with oxidative stress [2]. These mechanisms are essential to cell survival, since ROS can damage DNA, proteins and cell membranes.

One of these defense mechanisms is based on cytochrome $c$ peroxidases. These enzymes are $c$-type heme containing periplasmic enzymes that catalyze the reduction of hydrogen peroxide to water, using $c$-type

\footnotetext{
* Corresponding author.

E-mail address: srp@fct.unl.pt (S.R. Pauleta).
}

cytochromes or small type 1 copper proteins, of the respiratory chain, as electron donors $[3,4]$.

An example of such an electron donor is azurin, a member of a family of copper-containing, water soluble, low molecular weight redox proteins called cupredoxins, which function as electron shuttles in the electron transfer chain of several microorganisms, including some wellknown pathogens, such as Pseudomonas (Ps.) aeruginosa. These proteins have received great attention due to their unusual spectroscopy and electronic structure in the oxidized copper(II) form, as well as, their ability to transfer electrons rapidly to several enzymes [5,6].

Ps. aeruginosa azurin has been shown to be involved in the protection against oxidative stress, since a mutant lacking this protein was shown to be very sensitive to ROS [1,7]. In another pathogenic bacterium, $N$. gonorrhoeae, a mutant strain lacking the gene coding for a cupredoxin, the lipid-modified azurin (Laz), was found to be much more sensitive to hydrogen peroxide but not to superoxide, unlike the Ps. aeruginosa azurin mutant, resulting in reduced survival in human ectocervical epithelial cells [2].

The Neisseria lipid-modified azurin has a high sequence homology to other copper proteins from the azurin family [8,9], though it differs significantly from other members of this family in that it contains a N-terminal domain of 39 amino acids that encodes the H.8 epitope (common to pathogenic Neisseria), in which there are five imperfect 
repeats of the sequence Ala-Ala-Glu-Ala-Pro (AAEAP) [9,10] (Fig. 1). In addition, it is modified by a lipid group (palmityl fatty acid) at its $\mathrm{N}$-terminus [2,9,11], making Laz a lipoprotein bound to the outer membrane [10]. In fact, recently it has been shown using antibodies that $N$. meningitidis Laz is located at the outer membrane and that under certain growth conditions it can even be facing the outside of the cell [12]. Therefore, a similar location is expected for this protein in N. gonorrhoeae (tethered to the outer membrane and the facing periplasmic space).

The role of this electron shuttle protein is not completely established, since Neisseria genus has an array of periplasmic c-type cytochromes with apparent redundancy [13], shown to have complementary roles as electron shuttles in the respiratory chain of these microorganisms (Fig. 2). Neisseria genus can grow aerobically and microaerobically, as they present cytochrome $c b b_{3}$ oxidases with high affinity for oxygen, and can also use nitrite as an alternative electron acceptor, as they present an incomplete denitrification chain, composed by a copper nitrite reductase (AniA) and nitric oxide reductase NorB [14].

In Ps. aeruginosa, azurin can donate electrons to enzymes of the denitrification pathway, and thus, the role for Neisseria Laz as electron donor to AniA had been proposed, since these two proteins share the same cellular location, as being tethered to the outer membrane [10]. Nevertheless, in the case of $N$. gonorrhoeae, it was shown recently that the membrane bound cytochrome $c_{5}$ and $\mathrm{CcoP}$ are essential as electrons shuttles to AniA [13]. Therefore, the question remains as to the identity of the redox partner(s) of Laz in N. gonorrhoeae.

Based on primary sequence homology, Laz and azurin belong to the same cupredoxin family, the azurin-family [15]. These small redox proteins have distinct spectroscopic properties, with a strong absorption band at around $600 \mathrm{~nm}$ (with an $\varepsilon$ of 3-6 $\mathrm{mM}^{-1} \mathrm{~cm}^{-1}$ ), which has been assigned to a $\mathrm{S}_{\mathrm{cys}}-\mathrm{Cu}$ charge transfer band, and a redox potential higher than the one found in most inorganic copper complexes [16]. In cupredoxins, the copper atom adopts a distorted tetrahedral or bipyramidal geometry, with three of the four/five copper coordinating residues located at the C-terminus (Cys, His and Met) and the other(s) at the N-terminus. In the case of azurin, the fifth copper ligand is an oxygen from the carbonyl peptide bond of a glycine that is coordinating the copper atom, making the geometry more bipyramidal [15]. The structure of $N$. gonorrhoeae Laz incorporating $\mathrm{Zn}$ instead of $\mathrm{Cu}$ was recently determined by X-ray at 1.9 Å resolution (PDB ID 3AY2) [17]. In this work, we proceeded to solve the solution structure with $\mathrm{Cu}$ so as to evaluate any differences between $\mathrm{Zn}$-Laz and the native like form especially since $\mathrm{Zn}$ (II) prefers a quadrangular planar geometry.

This work focuses also on the biochemical characterization of $N$. gonorrhoeae Laz, as well as, on the determination of the solution structure of its cupredoxin domain. Results obtained show that Laz can donate electrons to cytochrome $c$ peroxidase from the same organism, which might explain the involvement of this cupredoxin in the defense against oxidative stress.

\section{Materials and methods}

\subsection{Protein purification}

The gene encoding the soluble part of Laz was cloned into a pET vector and the protein was heterologously produced in Escherichia coli
BL21(DE3), as reported in [18]. The transformed strained was grown in M9 medium [18], to label the protein with ${ }^{15} \mathrm{~N}$ or ${ }^{13} \mathrm{C} /{ }^{15} \mathrm{~N}$ and in LB medium supplemented with $0.5 \mathrm{mM} \mathrm{CuSO}_{4}$, for the biochemical characterization. The same induction conditions were used in both cases and the protein was purified in two chromatographic steps [18], an anionic exchange followed by a size-exclusion chromatography.

The purified Laz had a ratio of $A_{625} \mathrm{~nm} / A_{278} \mathrm{~nm}$ above 0.8 , when completely oxidized. The Laz preparations were considered to be pure as judged by Coomassie Blue stained SDS and native PAGE. The protein was stored at $-80^{\circ} \mathrm{C}$ until further use.

\subsection{Biochemical and spectroscopic characterization}

\subsubsection{Determination of the extinction coefficient}

Copper (I) content was determined using a modified version of the method of Hanna et al. [19], which is based on the formation of a complex between $\mathrm{Cu}^{\mathrm{I}}$ and 2,2'-biquinoline in an acetic acid medium. All solutions were prepared fresh in deionized water. A sample of Laz $(100 \mu \mathrm{L}$, containing 10-30 nmol of protein) or a standard solution of copper acetate was reduced by adding $300 \mu \mathrm{L}$ of $20 \mathrm{mM}$ sodium ascorbate (in $0.1 \mathrm{M}$ sodium phosphate at $\mathrm{pH} 6.0$ ) and incubated for $30 \mathrm{~min}$. To this, $600 \mu \mathrm{L}$ of a $2,2^{\prime}$-biquinoline solution $(0.5 \mathrm{mg} / \mathrm{mL})$ prepared in glacial acetic acid was added, and the solution was incubated for $10 \mathrm{~min}$ prior to the measurement of the absorbance at $546 \mathrm{~nm}$. The concentration of $\mathrm{Cu}^{\mathrm{I}}$ present in each sample was determined using the slope of the calibration curve prepared with copper(II) acetate. The extinction coefficient obtained $\left(6.3 \mathrm{mM}^{-1} \mathrm{~cm}^{-1}\right)$ was identical to that described by Hanna et al. [19]. The method used to quantify the total protein content was the BCA method (Sigma) [20], according to the manufacturer's instructions. The standard protein used was bovine serum albumin.

The extinction coefficient was determined taking into account the copper concentration of the sample, as a contamination with another copper protein is unlikely to occur, and it is rather difficult to have a pure protein sample (usually considered as pure when it is $>95 \%$ purity).

\subsubsection{Determination of molecular mass}

The molecular mass of the purified Laz was determined by electrospray ionization mass spectrometry (ESI-MS). The apparent molecular mass of Laz was estimated by molecular-exclusion chromatography, using a Superdex 75 10/300 GL (GE Healthcare). The column was equilibrated with $50 \mathrm{mM}$ Tris-HCl, pH 7.6 with or without $150 \mathrm{mM} \mathrm{NaCl}$. Samples of oxidized Laz ( $1 \mathrm{nmol}$ ) were prepared in the running buffer. A calibration curve was prepared using the Gel Filtration Calibration Kit Low Molecular Weight (GE Healthcare) in the same running buffer, according to the manufacturer's instructions. The chromatograms together with the analysis of this data are shown as Supplementary material (Fig. S1 and Fig. S2).

\subsubsection{Spectroscopic characterization}

The visible-spectra were recorded on a Shimadzu UV-1800 spectrophotometer using $1 \mathrm{~cm}$ quartz cells. Laz samples were oxidized with a solution of potassium ferricyanide and reduced with a solution of sodium ascorbate.

The Laz sample for EPR was $0.3 \mathrm{mM}$ in $20 \mathrm{mM}$ phosphate buffer, pH 7.0. The EPR spectra of Laz were recorded on a X-band Bruker EMX

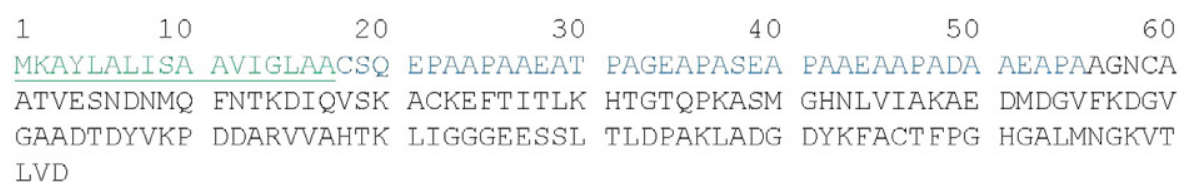

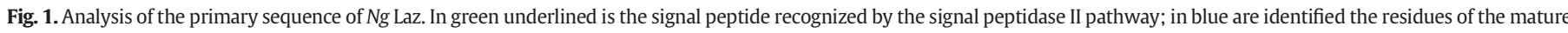
protein recognized by the epitope for the H.8 MAb; and in black the azurin-like domain. 


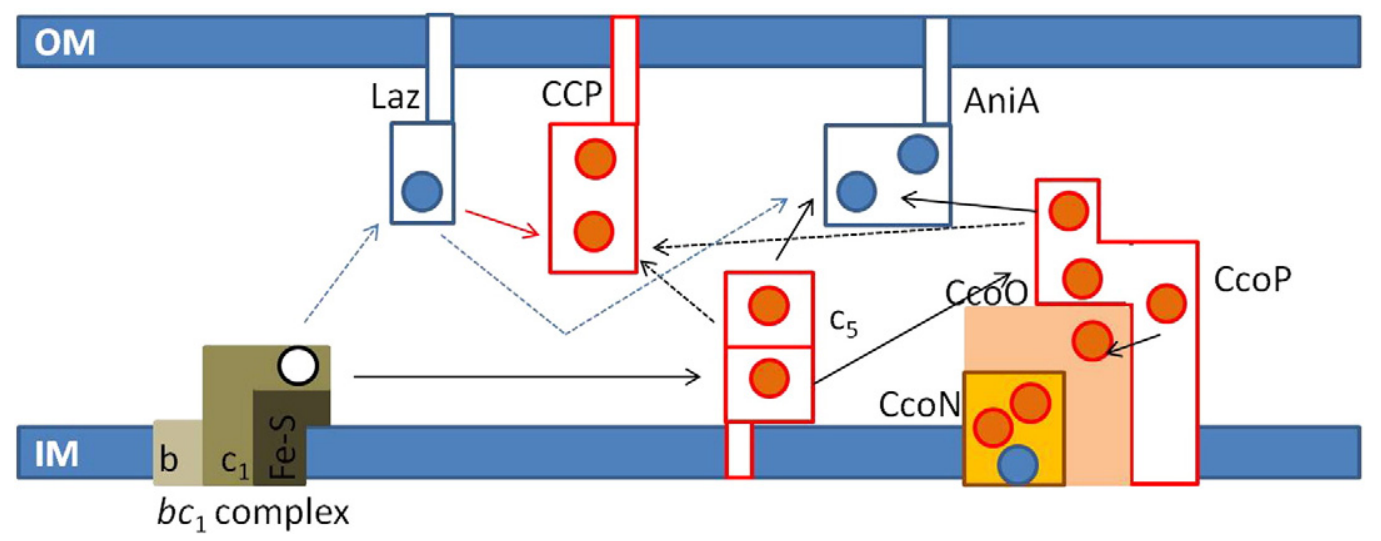

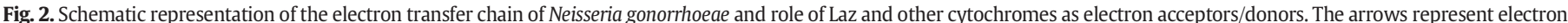

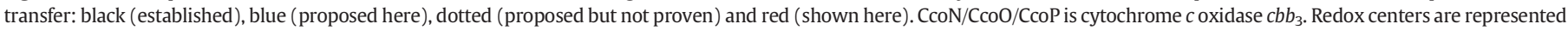

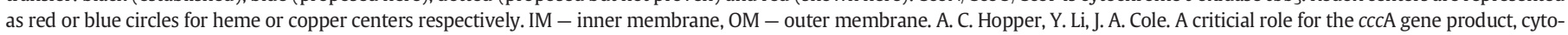
chrome $c_{2}$, in diverting electrons from aerobic respiration to denitrification in Neisseria gonorrhoeae.

spectrometer equipped with a rectangular cavity (model ER 4102T) and an Oxford Instruments continuous liquid helium flow cryostat. Experimental conditions are described in the legend of the spectrum. The simulation of the spectrum was performed using WINEPR SimFonia software version 1.2, from Bruker.

\subsubsection{Redox potential}

Voltammetric measurements were performed on a potentiostat AUTOLAB/PSTAT 12 (ECO Chemie, Utrecht, The Netherlands). Data were collected and analyzed using GPES software package (ECO Chemie). The electrode potential values reported here were referred to the standard hydrogen electrode (SHE). Voltammetric experiments were conducted at room temperature using a three-electrode configuration cell with a saturated $\mathrm{Ag} / \mathrm{AgCl}$ reference electrode $(+197 \mathrm{mV}$ vs SHE at room temperature), a platinum wire as the counter electrode and an edge plane pyrolytic graphite (PGE) as the working electrode. Nitrogen gas was purged through the solution for at least $15 \mathrm{~min}$ to remove any dissolved oxygen before each experiment.

Before each experiment, the PGE surface was polished by hand on a polishing cloth using a 1 and $0.3 \mu \mathrm{m}$ alumina slurry, sonicated for $5 \mathrm{~min}$ and rinsed well with Milli-Q water. The electrode was prepared by dropping a $3 \mu \mathrm{L}$ drop of working solution containing Laz $(145 \mu \mathrm{M})$ and left to dry at room temperature for $1 \mathrm{~h}$. The scan-rate dependence of the current was measure between 5 and $150 \mathrm{mV} / \mathrm{s}$, in a solution containing $100 \mathrm{mM}$ phosphate buffer $\mathrm{pH} 7.0$ and $100 \mathrm{mM} \mathrm{NaCl}$.

The $\mathrm{pH}$ dependence of the redox potential was determined in the $\mathrm{pH}$ range from 5.5 to 8.5 , in a solution containing $20 \mathrm{mM}$ of acetate, 2-morpholinoethanesulfonic acid, 2-[4-(2-hydroxyethyl)piperazin1-yl] ethanesulfonic acid and $\mathrm{N}$-[tris(hydroxymethyl)methyl]-3aminopropanesulfonic acid. The reduction potential was determined for each $\mathrm{pH}$ at $10 \mathrm{mV} / \mathrm{s}$ scan rate. The $\mathrm{pH}$ dependence of the reduction potential was defined by one equilibrium and two $\mathrm{pK}_{\mathrm{a}}$ values. The data was fitted to Eq. 1, according to the equilibrium shown in the inset of Fig. 4B.

$E^{\circ \prime}=E_{\mathrm{lp}}^{\circ \prime}+\frac{2.3 \mathrm{RT}}{\mathrm{nF}} \log _{10}\left(\frac{1+\left(\frac{K_{o R}}{\left[H^{+}\right]}\right)}{1+\left(\frac{K_{o O}}{\left[H^{+}\right]}\right)}\right)$

In the equation, $\mathrm{E}^{0 /}$ is the measured reduction potential, $E_{l p}^{\circ}$ is the reduction potential at low $\mathrm{pH}$, and $\mathrm{K}_{\mathrm{aO}}$ and $\mathrm{K}_{\mathrm{aR}}$ are the proton dissociation constants of the oxidized and reduced forms, respectively. A non-linear regression fit (with no fixed parameters) in Excel was used to estimate the parameters: $\mathrm{E}_{\mathrm{lp}}^{0}{ }^{\prime}=294 \pm 5 \mathrm{mV}, \mathrm{pK}_{\mathrm{aO}}=6.8 \pm$ 0.2 and $\mathrm{pK}_{\mathrm{aR}}=7.9 \pm 0.2$.

\subsubsection{Kinetic assays}

The activity of $N$. gonorrhoeae cytochrome $c$ peroxidase ( $N g$ CCP) with Laz as electron donor was monitored on an Agilent Diode Array spectrophotometer, by the increase in absorbance at $625 \mathrm{~nm}$ as result of Laz oxidation over time. Laz was reduced with $1 \mathrm{mM}$ sodium ascorbate and $10 \mu \mathrm{M}$ DAD for $30 \mathrm{~min}$ at room temperature, which were removed using a desalting column, NAP-5 (GE Healthcare), equilibrated with $10 \mathrm{mM}$ MES, pH 6.0.

The E. coli periplasmatic fraction containing heterologously expressed $\mathrm{Ng}$ CCP in E. coli BL21(DE3) was used directly in the assay (data not shown, $\mathrm{Ng}$ CCP gene was inserted into pET22-b, and coexpressed with pEC86 [21]). As a control experiment, a periplasmatic fraction of the same $E$. coli strain co-transformed with pEC86 and pET22b, without the gene encoding $\mathrm{Ng} \mathrm{CCP}$, and grown in same conditions was used. The periplasmic extract was obtained by 5 freezethaw cycles of the resuspended cells, followed by centrifugation at 48,000 $\mathrm{g}$ in an Avanti J-26 XPI centrifuge (Beckman Coulter), during 10 min, at $4{ }^{\circ} \mathrm{C}$.

The assay was performed at $25^{\circ} \mathrm{C}$ in $10 \mathrm{mM}$ MES pH 6.0 containing $10 \mathrm{mM} \mathrm{NaCl}$ and $1.0 \mathrm{mM} \mathrm{CaCl}_{2}$. The order of the assay additions was: buffer, Laz to the final concentration of $11 \mu \mathrm{M}, 0.02$ or $0.004 \mu \mathrm{g}$ of total protein of periplasmatic fraction, and $100 \mu \mathrm{M} \mathrm{H}_{2} \mathrm{O}_{2}$ to initiate the assay. In the end, a small aliquot of potassium ferricyanide solution was added to fully oxidize and confirm that all Laz was oxidized in the assay.

\subsection{NMR experiments and structure determination}

The NMR samples were $1.5 \mathrm{mM}$ Laz in $20 \mathrm{mM}$ sodium phosphate, $\mathrm{pH} 7.0,1 \mathrm{mM}$ sodium azide, $5 \mathrm{mM}$ sodium ascorbate and $10 \%{ }^{2} \mathrm{H}_{2} \mathrm{O}$. Sodium ascorbate was used to reduce the copper site of the protein, making it diamagnetic [18]. NMR data was collected, at $298 \mathrm{~K}$, on a Bruker AvanceIII $800 \mathrm{MHz}$ equipped with a TXI-HCN gradient probe and on a Bruker AvanceIII $600 \mathrm{MHz}$ equipped with a TCI-cryoprobe. Resonance assignments have already been reported [18] and deposited in the BioMagResBank (http://www.bmrm.wisc.edu) under BMRB accession number 18636.

The NOE data from reduced Laz were obtained from the ${ }^{1} \mathrm{H}^{13} \mathrm{C}$ HSQC-NOESY experiment, acquired simultaneously with a ${ }^{1} \mathrm{H}^{15} \mathrm{~N}$ HSQC-NOESY experiment [22], with a mixing time of $120 \mathrm{~ms}$.

ARIA2.3 [23] and CNS1.21 [24,25] were used for NOE assignment and structure calculation. TALOS-N [26] was used to predict dihedral 
angles and the respective restraints were used in the calculations. The ARIA2.3 protocol using flat-bottom potential was used to validate the NOE distance restraints and no consistent violations were found. The restraints were then used in the log-harmonic potential protocol [27] with automatic weight determination $\left(10.5 \mathrm{kcal} / \mathrm{mol} / \AA^{2}\right)$ to calculate 100 structural models. The ten lowest energy models were water refined with CNS1.21. Structural calculations were performed with and without the $\mathrm{Cu}(\mathrm{I})$ atom. To include the copper center in the calculations the same approach used for $\mathrm{Zn}$ centers available in ARIA2.3 was followed. $\mathrm{A} \mathrm{Cu}(\mathrm{I})$ residue and a copper center pseudo residue, which creates the polypeptide-metal bonds, were added to the topology file (topallhdg5.3.pro). The bond lengths and angles values were based on the average values from $\mathrm{Cu}$ centers from homologous proteins (PDB IDs: 4azu, 1rkr, 1uat, 2aza, 1joi, 1dz0, 1e5z, 2ccw and 1nwp) and defined in the parameter file (parallhdg5.3.pro). The $\mathrm{Cu}(\mathrm{I})$ atom mass and non-bonded parameters used were the ones present in the ion.top and ion.param files from CNS1.21, respectively (see description of the files in the Supplementary materials).

The restraints used for the structure calculations are summarized in Table 1. The validation of the data was performed using CING [28]. The NMR data was deposited in the BioMagResBank (www.bmrb.wisc. edu) under accession number 18636 and the coordinates used for the ensemble of NMR structures have been deposited in the Protein Data Bank (http://www.rcsb.org/) under the PDB ID 2n0m.

As a remark, a disulfide bond was identified between C6 and C29 based on the NOE observed between the $\mathrm{H}^{\beta}$ protons of these two residues. This was added as a patch in the preparation of the calculation and not added as a restraint.

The RMSD between average NMR structure and the X-ray structure (PDB ID: 3AY2) was determined using the online tool SuperPose version 1.0 (http://wishart.biology.ualberta.ca/).

Table 1

Summary of structural statistics obtained for the reduced Neisseria Laz. The statistics presented are for the 10 lowest energy structures after water refinement.

\begin{tabular}{ll} 
Number of distances and dihedral angle constraints & \\
NOE-distance constraints & 3345 \\
Intra-residue & 968 \\
Sequential & 699 \\
Medium range $(1<|\mathrm{i}-\mathrm{j}|<5)$ & 373 \\
Long range $(|\mathrm{i}-\mathrm{j}|>4)$ & 1305 \\
Ambiguous & 169 \\
Dihedral angle constraints & 65 \\
Constraints statistics & \\
r.m.s.d. of distance violations & $0.154 \pm 0.014$ \\
r.m.s.d. of dihedral violations & $0.247 \pm 0.059$ \\
Structure r.m.s.d. & \\
Backbone & $0.57 \pm 0.07$ \\
Heavy atoms & $0.93 \pm 0.06$ \\
Structural quality & \\
Ramachandran (PROCHECK) & \\
Most favored regions & $86.1 \%$ \\
Allowed regions & $13.4 \%$ \\
Generously allowed regions & $0.4 \%$ \\
Disallowed regions & $0.1 \%$ \\
WHATIF Z-scores & \\
Backbone conformation & $-0.232 \pm 0.355$ \\
2nd generation packing quality & $7.349 \pm 2.394$ \\
Ramachandran plot appearance & $-1.799 \pm 0.514$ \\
$\chi^{1} / \chi^{2}$ rotamer quality & $-3.056 \pm 0.447$ \\
CING ROG analysis & \\
Red & $15 \%$ \\
Orange & $22 \%$ \\
Green & $63 \%$ \\
\hline
\end{tabular}

\section{Results and discussion}

\subsection{Cloning and protein production}

The analysis of the primary sequence of the ORF annotated as coding for the lipid-modified azurin from $N$. gonorrhoeae, indicates the presence of two regions at the $\mathrm{N}$-terminus prior to the azurin-like domain of 128 residues. The first 17 residues at the $\mathrm{N}$-terminus, are predicted to be recognized and processed by the signal peptidase II, and are followed by 39 residues, that constitute the epitope for H.8 MAb binding. This stretch of 39 residues is constituted by imperfect repeats of AAEAP [9] (Fig. 1).

The mature protein is proposed to be composed of the azurin-like domain together with the 39 residue $\mathrm{N}$-terminal sequence, that is modified at the second cysteine residue with a diacylglyceride $[9,10]$, and thus its cellular localization has been proposed to be the outer membrane with the azurin-like domain facing the inside of the periplasmic space $[10,12]$, similarly to other gonococcal proteins, such as AniA, a copper containing nitrite reductase [29], and bacterial cytochrome $c$ peroxidase [30].

In order to obtain soluble protein for the structural characterization, the DNA sequence corresponding to this soluble azurin-like domain was cloned into a pET expression vector, with the signal peptide of Paracoccus pantotrophus pseudoazurin, which was previously shown to be well recognized by the E. coli Sec-dependent pathway [31].

The expression conditions of laz gene in E. coli were optimized, and in order to obtain Laz in the soluble periplasmic extract, the transformed cells had to be grown at $16{ }^{\circ} \mathrm{C}$ during $7 \mathrm{~h}$, after induction with IPTG. Laz in the periplasmic extract was mostly in the reduced state, as upon addition of some crystals of potassium ferricyanide, a bright blue color appears. The yield of the expression was $50 \mathrm{mg}$ and $20 \mathrm{mg}$ of purified Laz/L of rich and M9 medium, respectively.

The isolated Laz has a ratio of $A_{625} \mathrm{~nm}$ of the oxidized to $A_{278} \mathrm{~nm}$ of the untreated sample, of approximately 0.8 or higher, and could be considered pure judged by its SDS-PAGE. The amount of copper per total protein was determined to be $0.79 \pm 0.04$, as expected for a cupredoxin (with $1 \mathrm{Cu} /$ protein).

The heterologously produced Laz has an apparent molecular mass of $21 \pm 2 \mathrm{kDa}$ or $25 \pm 2 \mathrm{kDa}$ in $50 \mathrm{mM}$ Tris- $\mathrm{HCl}, \mathrm{pH} 7.6$, in the presence or absence of $150 \mathrm{mM} \mathrm{NaCl}$, respectively (Figs. S1 and S2, Supplementary material). These values could indicate that Laz exhibits a monomerdimer equilibrium (since the expected molecular mass from the primary sequence is $13,633.3 \mathrm{kDa}$ and the one determined by ESI-MS was $13,631 \pm 1 \mathrm{Da})$. Nevertheless, backbone ${ }^{15} \mathrm{~N}$ relaxation studies at the $800 \mathrm{MHz}$ NMR spectrometer of the reduced form at low ionic strength ( $500 \mu \mathrm{M} \mathrm{Laz}$ in $20 \mathrm{mM}$ phosphate buffer, $\mathrm{pH} 7.0$ ) gave an average $\mathrm{R} 1$ of $1.18 \pm 0.05 \mathrm{~s}^{-1}$ and an R2 of $10.0 \pm 0.1 \mathrm{~s}^{-1}$. The resulting value of R2/R1 of 8.46 is consistent with a monomeric protein $\left(\tau_{c}\right.$ of $6.5 \pm 0.1 \mathrm{~ns}$ ). In addition, the oxidized and reduced forms (at the same conditions) exhibited identical diffusion rates and R1 and $R 2$ values, suggesting that the oxidized protein is also not a dimer under NMR conditions. Thus, the discrepancy between the two methods of molecular size determination could be attributed to the elongated $\beta$-barrel structure (vide infra) of Laz (higher Stokes volume) and to the need of a calibration curve with "standard proteins" in the size-exclusion chromatography.

\subsection{Spectroscopic characterization}

Laz visible spectrum, shown in Fig. 3A, has a maximum absorption band at $625 \mathrm{~nm}$. This absorption band has an extinction coefficient of $5.1 \mathrm{mM}^{-1} \mathrm{~cm}^{-1}$ (considering the copper quantification), and has a ligand-to-metal charge transfer character of $\mathrm{S}_{\mathrm{cys}}$ to $\mathrm{Cu}$ ion: CysS $\pi \rightarrow \mathrm{Cu}^{2+}\left(\mathrm{d} x^{2}-y^{2}\right)$ [32], which is characteristic of the type 1 copper proteins, and responsible for its intense blue color [33]. This other spectroscopic feature of Laz is the small hyperfine coupling constant $(A \|)$ of 
A)

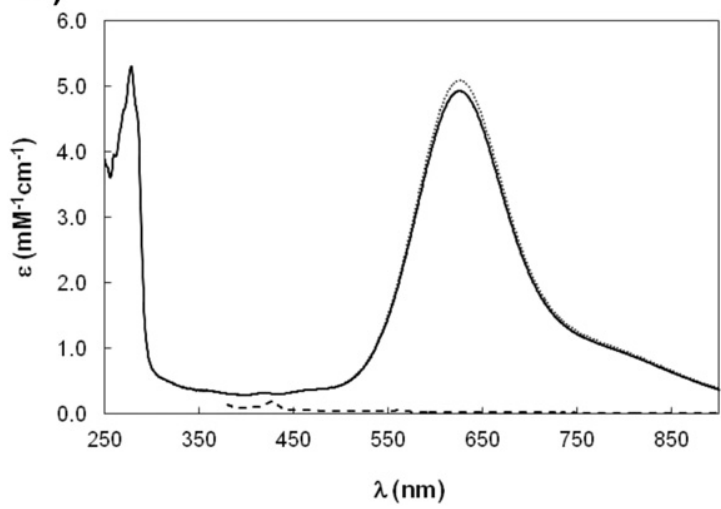

B)

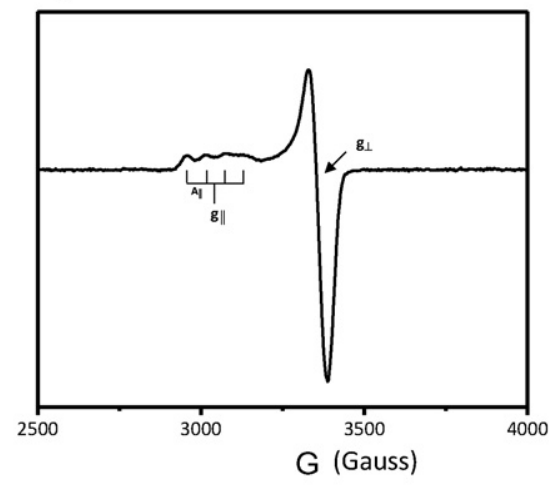

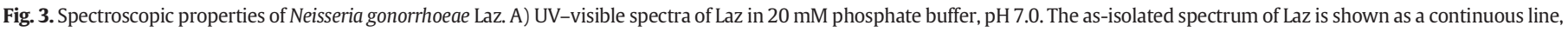

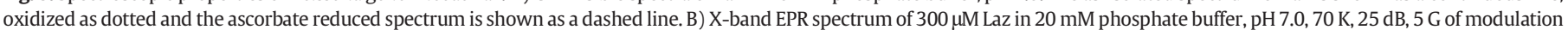
and $1 \times 10^{5}$ gain.

57 gauss [34,35], in the EPR spectrum of Laz (Fig. 3B), with $g|| 2.266$ and $\mathrm{g}_{\perp} 2.048$, which is due to the highly covalent character of the $\mathrm{Cu}^{2+}$ $\mathrm{S}$ (cys) $\pi$ bond (vide infra, short distance between of $\mathrm{Cu}-\mathrm{S}-\mathrm{Cys}$ ).

The wavelength of the maximum absorption in azurin and in Laz is redshifted by around $30 \mathrm{~nm}$, when compared to other cupredoxins, which has been attributed to the existence of a disulfide bond between two N-terminal $\beta$-strands (vide-infra) [16].

In fact, the maximum absorption band occurs at the same wavelength as the one observed for soluble azurins isolated from different microorganisms, such as Ps. aeruginosa [36,37], Pseudomonas chlororaphis [38] and Alcaligenes denitrificans [39]. Likewise, the EPR parameters are very similar to ones of cupredoxins that belong to the azurin-family [38-40].

\subsection{Redox properties of Laz}

The electrochemical behavior of Laz form $N$. gonorrhoeae was analyzed at a PGE by protein film voltammetry in a solution containing $100 \mathrm{mM}$ phosphate $\mathrm{pH} 7.0$ and $100 \mathrm{mM} \mathrm{NaCl}$. Cyclic voltammograms obtained for different scan rates $(5 \leq v \leq 150 \mathrm{mV} / \mathrm{s}$ ) have quite symmetrical oxidation and reduction peaks as can be observed in Fig. 4A.

Analysis of the voltammograms shows that the peak currents $\left(i_{\mathrm{p}}\right)$ vary linearly with $v$, indicative of a diffusionless one-electron redox process with both the oxidized and the reduced forms being adsorbed. The ratio of the cathodic and anodic peak currents $\left(i_{\mathrm{pa}} / i_{\mathrm{pc}}\right)$ are independent of $v$ and close to 1 for all scan rates. The width of half height $\left(\Delta \mathrm{Ep}_{1 / 2}\right)$ for anodic and cathodic peak has a value close to $90 \mathrm{mV}$.

Laz electrochemical behavior shows a reversible system of one electron process and a formal potential could be calculated. For all scan rates, the average of $\mathrm{E}$ is constant within the experimental error and a formal reduction potential $E^{\circ \prime}=277 \pm 5 \mathrm{mV}$ was estimated at $\mathrm{pH}$ 7.0. The value of the estimated formal potential is similar to the one reported for azurin from Ps. aeruginosa $(+267 \mathrm{mV})$ immobilized on a PGE [41].

The $\mathrm{pH}$ dependence of the reduction potential (Fig. 4B) shows that this value decreases with $\mathrm{pH}$. The variation observed can be fitted with two pKa values, one for the reduced and another for the oxidized form of $\mathrm{Laz} \mathrm{pK}_{\mathrm{aO}}(6.8 \pm 0.2)$ and $\mathrm{pK}_{\mathrm{aR}}(7.9 \pm 0.2)$, which are similar to the ones determined for Ps. aeruginosa azurin by electrochemistry using a PGE, (7.1 and 7.8, respectively) [42]. In the absence of additional biochemical data on Laz, these pKa values can be attributed to an ionizable group close to the copper center, probably a histidine residue due to the pKa values determined, as in the case of Ps. aeruginosa azurin (His35) $[40,42]$. In fact, this residue is conserved in the azurin family (in Laz it is His38) and is located in the second coordination sphere of the copper center [42]. In the case of Ps. aeruginosa azurin, the results
A)

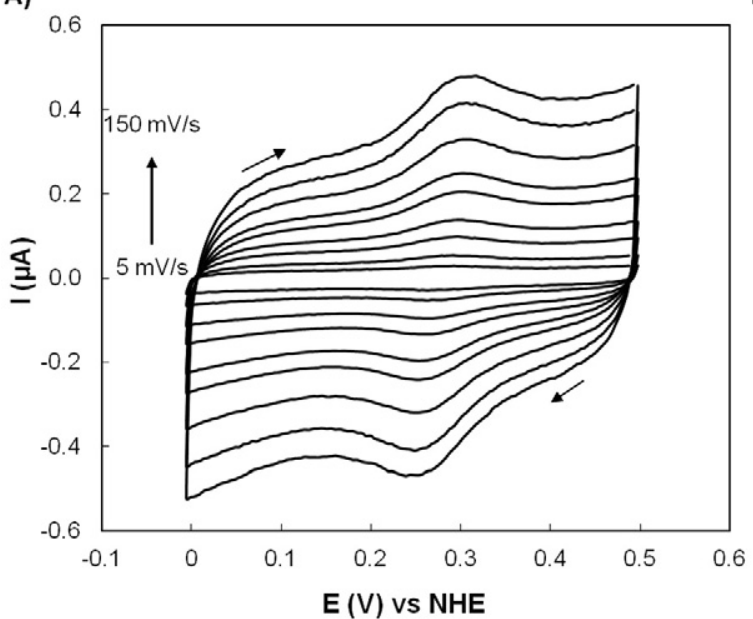

B)

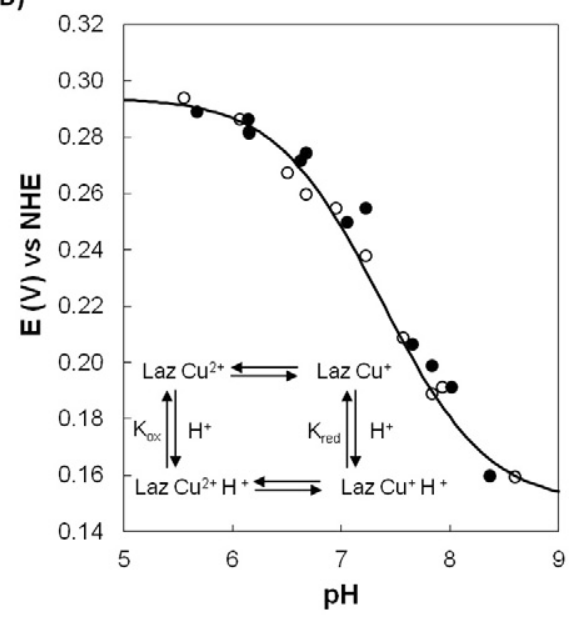

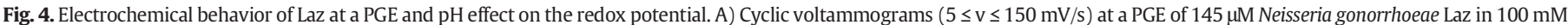

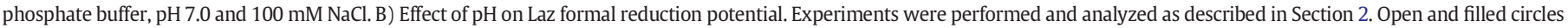

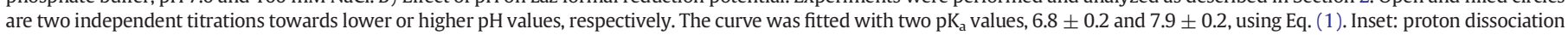
equilibria for the $\mathrm{pK}$ pair. 
obtained by EPR, NMR and EXAFS, together with the X-ray structure of this protein at high $\mathrm{pH}$, led to the proposal that upon deprotonation, the imidazole side chain of His35 reorients, leading to a reorganization of polypeptide chain around the copper center and changing the hydrogen bond network involving His35 [40,43]. A similar event can be proposed to occur here.

\subsection{NMR structure of Laz}

The NMR structure of Laz was determined for the reduced state, which is diamagnetic, in order to avoid the relaxation enhancement effect of the paramagnetic $\mathrm{Cu}(\mathrm{II}), \mathrm{S}=1 / 2$, which would lead to linewidth broadening beyond detection and/or large chemical shift deviation of atom resonances in a $5 \AA$ sphere from the metal ion.

The structure was determined using a total of around 3300 NOEdistance constraints (26 per residue, Fig. S5) and 65 dihedral angle constraints, with the complete statistics shown in Table 1.

It is worth mentioning that about 1300 of the total NOEs are long range distance restraints (39\%), which results in a final number of 10 long range NOEs per residue. The per-residue global displacement in the 10 lower energy structures to the mean structure (calculated after superimposition for minimal RMSD of all backbone atoms, Fig. S4) identifies that apart from the 5 first residues, the structure is well-defined (Fig. S5), with a backbone r.m.s.d below $0.6 \AA$ A, except for three more flexible loops, 38-41, 77-80 and 105-107, that are located after $\beta 3$ and before $\beta 5$ and $\beta 7$, respectively. The copper ligands and its surroundings are also well-defined.

The Laz has the typical cupredoxin fold of the azurin-family [15], consisting of an eight-stranded $\beta$-barrel formed by two anti-parallel $\beta$-sheets arranged in the Greek key motif (Fig. 5A), with a helix after $\beta 4$ (residues 58-68). Sheet 1 is composed of $\beta 1$ (residues 6-12), $\beta 3$ (residues 32-39) and $\beta 6$ (residue 93-99) and sheet 2 composed of $\beta 2$ (residues 21-27), $\beta 4$ (residues 51-56), $\beta 5$ (residues 84-86), $\beta 7$ (residues 108-113) and $\beta 8$ (residue 122-129). This very rigid well-packed hydrophobic core and $\beta$-barrel structure explains the high number of long range NOEs per residue that were assigned.

Like in other azurins $[43,44]$, there is a disulfide bond between cysteine residues 6 and 29, which was identified by the typical chemical shift of the $C \beta$ of these residues for an oxidized cysteine and by the strong NOE observed between the $\mathrm{H}^{\beta}$ protons of Cys6 and Cys29, in the earlier stages of the structure calculation. This disulfide bond connects the two N-terminal $\beta$-strands ( $\beta 1$ and $\beta 2$ ). Just as a note, all the proline residues are in the cis conformation based on the chemical shift of their $C \beta$ and $C \gamma$.

The copper center in Laz is coordinated by N81His49 $(2.1 \pm 0.1 \AA$ to $\mathrm{Cu}), \mathrm{S} \gamma \mathrm{Cys} 113(2.2 \pm 0.1 \AA \AA$ to $\mathrm{Cu}), \mathrm{N} \delta 1 \mathrm{His} 118(2.1 \AA \pm 0.1$ to $\mathrm{Cu})$, carbonyl O Gly48 ( $2.9 \pm 0.1 \AA \AA$ to $\mathrm{Cu}$ ), and SsMet122 (3.1 \pm 0.1 Å to $\mathrm{Cu})$, in a pseudotrigonal bipyramidal geometry (Fig. $5 \mathrm{~B}$ ). This geometry is similar to the one of Cu center of azurin [43-45], with the trigonal plane defined by the cysteine and the two histidine ligands [43-45]. These distances are within the average found in the azurin copper center in the oxidized or reduced state (PDB ID: 4azu, PDB ID: 1e5y, respectively).

It is also interesting to mention that the backbone structure and the position of the copper ligands almost does not change in the absence of the constraints to the copper atom. In fact, a new structural bundle was calculated without the $\mathrm{Cu}$ atom and respective bonds. The $\mathrm{C} \alpha-\mathrm{C} \alpha$ RMSD between the two bundles is $0.63 \AA$, while the all atom RMSD of the $\mathrm{Cu}$ binding residues is $0.92 \AA$. These numbers translate only into small rearrangements of the side chains of the residues forming the $\mathrm{Cu}$ center (mainly rotation of the side-chain of Met122 and His49), when the $\mathrm{Cu}$ atom and bonds are present (Fig. S6, Supplementary materials).

This fact is supportive of the entatic or rack-induced state hypothesis initially proposed by Vallee \& Williams $[47,48]$. In this hypothesis the protein backbone exerts a strain on the copper atom, and thus the geometry of the reduced and oxidized copper center is almost identical, minimizing the reorganization energy of the electron transfer process. As a consequence the electron transfer rates are enhanced, which explains the high self-exchange rate constants found in cupredoxins, when compared with the ones of $\mathrm{Cu}(\mathrm{II}) / \mathrm{Cu}(\mathrm{I})$ small complexes, and their electronic properties.

As a remark, the structure reported here is similar to one determined for the Zn-Laz from the same organism using X-ray crystallography (PDB ID 3AY2) [17], with a backbone RMSD of $0.6 \AA$ and an all atom RMSD of $1.2 \AA$

The electrostatic surface of Laz presented in Fig. 5C shows that the surface containing the surface exposed His118 edge, one of the copper ligands, is hydrophobic but without any specific charged patch. Most of these small redox proteins have patches of positive or negative charges, usually as a ring surrounding a hydrophobic region, which are proposed to be critical in the orientation of the small protein towards the partner, while the hydrophobic patch contributes to the stabilization of the active transient electron transfer complex and also to a high electron transfer rate $[4,49]$.

The fact of Laz being tethered to the outer membrane through a flexible linker will increase its local concentration, and thus the need for pre-orientation prior to electron transfer complex formation, in which charged patches would be instrumental, decreases. Moreover, the absence of a strong positive patch at the protein surface (not shown) might also be important to allow Laz to interact with its redox partner and not be associated with the membrane in unproductive orientations.

Moreover, the absence of clear charged patches together with the increase in its local concentration, might indicate that the electron complexes formed with Laz have a more dynamic nature, with several effective orientations. In case the redox partner is also tethered to the
A)

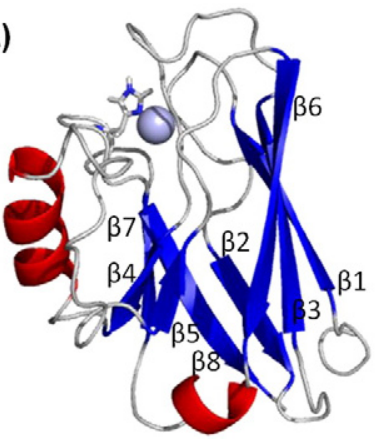

B)

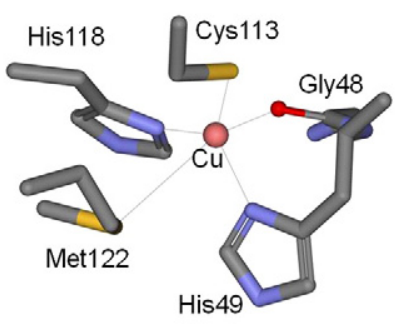

C)

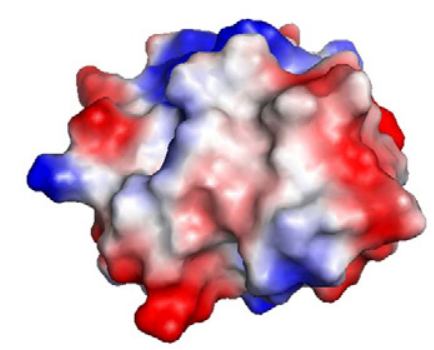

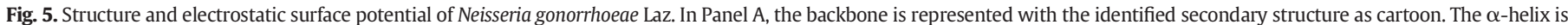

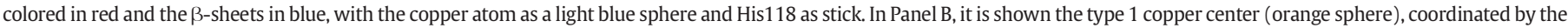

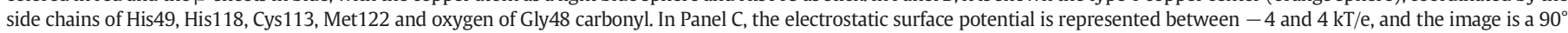
rotation of the one in Panel A, so that the proposed electron entry site is facing the reader (His118). Figures were prepared using PyMol Viewer. 
outer membrane (vide infra), the need for the two proteins to diffuse towards each other does not exist and thus the formation of a productive complex has a higher probability to occur.

\subsection{Laz as electron donor to Neisseria cytochrome c peroxidase}

Initially, Laz was proposed to be the electron donor to AniA, a copper nitrite reductase, as both proteins are outer membrane proteins [10], and in other microorganisms as Ps. aeruginosa, azurin has a prominent role in electron shuttling in the periplasm during denitrification [50]. However, recently, it was shown that in N. gonorrhoeae a Laz mutant strain could reduce nitrite either under aerobic or microaerobic conditions at similar rate as the wild-type strain [13], and that cytochrome $c_{5}$ and $\mathrm{CcoP}$, a dihemic and trihemic membrane bound cytochromes, respectively, are essential to maintain nitrite reduction by this microorganism [13] (Fig. 2).

Although, it could still be speculated that Laz might donate electrons to AniA, but can only be reduced by one of those cytochromes, its role may be associated with electron shuttling to cytochrome $c$ peroxidase, which is also bound to the outer membrane. In fact, a Laz mutant $N$. gonorrhoeae strain was shown to be more sensitive to hydrogen peroxide stress [2] than the wild-type strain.

In order to test the hypothesis that Laz functions as electron donor to cytochrome $c$ peroxidase, the periplasmic extract of $E$. coli heterologously expressing $N$. gonorrhoeae bacterial cytochrome $c$ peroxidase was prepared, and used to determine whether in its presence there was Laz oxidation upon addition of hydrogen peroxide. This oxidation rate corresponds to the electron transfer between reduced Laz and the enzyme in the presence of hydrogen peroxide (Fig. 6). These electrons are required to maintain the catalytic cycle of cytochrome $c$ peroxidase during the reduction of the substrate.

In fact, a significant Laz oxidation rate is only observed in the presence of a periplasmic extract from $E$. coli cells that produce the $N$. gonorrhoeae bacterial peroxidase. Another assay was carried out, using in substitution to reduced Laz, reduced horse cytochrome $c$, but no oxidation of Laz was detected using the same periplasmic extracts (data not shown). This is an excellent evidence that Laz can donate electron to the bacterial cytochrome

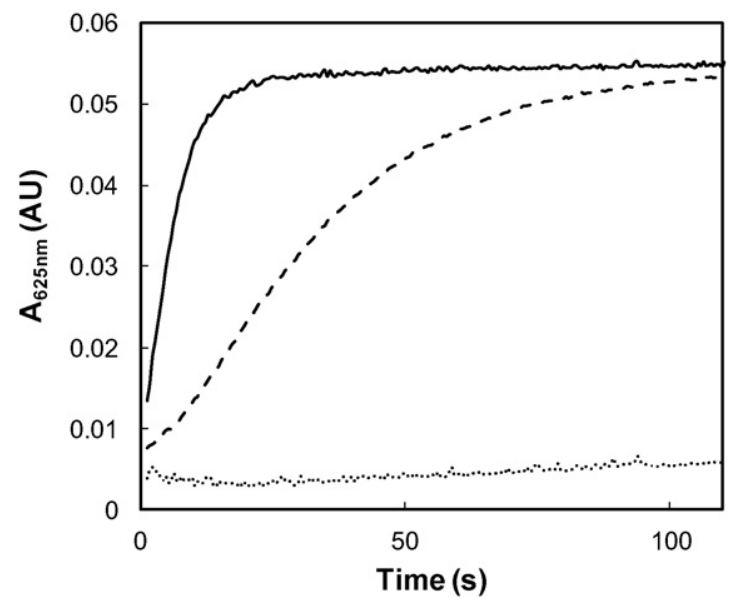

Fig. 6. Neisseria gonorrhoeae Laz is a competent electron donor to cytochrome $c$ peroxidase from the same organism. Laz oxidation rate in the presence of $0.02 \mu \mathrm{g}$ protein (full line) or $0.004 \mu \mathrm{g}$ of protein (dashed line) from the periplasmic extract $E$. coli $/ \mathrm{NgCCP} / \mathrm{pEC} 86$, and $0.02 \mu \mathrm{g}$ of periplasmic extract E. coli/pET22b/pEC86 (dotted line), after addition of hydrogen peroxide. The assays were performed as described in Section 2, and the initial rates were determined to be $0.86 \pm 0.08,0.12 \pm 0.01$ and $\sim 0 \mu \mathrm{M} \mathrm{Laz} / \mathrm{s}$, respectively (after subtraction of the initial oxidation rate in the presence of the periplasmic extract). Time was adjusted to the addition of $\mathrm{H}_{2} \mathrm{O}_{2}$, as time $0 \mathrm{~s}$ (a complete kinetic trace is shown in Supplementary materials, Fig. S3). c peroxidase from $N$. gonorrhoeae. The complete kinetic and structural characterization of this interaction is being carried out.

\section{Conclusions}

The soluble domain of Laz, a lipid-bound copper protein, of $N$. gonorrhoeae, was heterologously produced in the periplasm of $E$. coli. This protein has all the spectroscopic properties, as well as, the fold of a cupredoxin of the azurin-family. The analysis of the electrostatic surface of Laz indicates the presence of a hydrophobic patch around the exposed histidine edge that coordinates the copper atom and is proposed to be the electron entry/exit, but the presence of charged patches that could be required for the orientation of Laz towards the redox partner(s) is not observed. This distinct property might be a direct consequence of the tethering of this protein to the outer membrane and the evolutionary pressure of the environment to which $N$. gonorrhoeae is subjected: cannot freely diffuse in the periplasm and the presence of variable ionic strength that would have hindered the interaction, if it would be governed by electrostatic forces. In addition, the absence of a positive charged patch avoids its association with the membrane and increases the probability of producing productive encounter complexes with cytochrome $c$ peroxidase.

Here, it is proposed that one of the redox partners of Laz is cytochrome $c$ peroxidase, that catalyses the reduction of hydrogen peroxide to water. The activity of this enzyme is vital for the survival of $N$. gonorrhoeae in the host upon exposure to oxidative stress during infection. Thus, the formation of this complex explains why a Laz mutant strain of Neisseria gonorrhoeae is more sensitive to hydrogen peroxide [2].

\section{Transparency document}

This Transparency document associated with this article can be found, in online version.

\section{Acknowledgments}

We thank Fundação para a Ciência e Tecnologia (FCT) for the financial support provided to SRP (PTDC/BIA-PRO/109796/2009), CSN (SFRH/BD/87878/2012) and IHS (SFRH/BPD/84404/2012), and that support the $600 \mathrm{MHz}$ and $800 \mathrm{MHz}$ NMR spectrometers that are part of the National NMR Network (RECI/BBB-BQB/0230/2012).

\section{Appendix A. Supplementary data}

Supplementary data to this article can be found online at http://dx. doi.org/10.1016/j.bbabio.2015.11.006.

\section{References}

[1] K.L. Seib, H.J. Wu, S.P. Kidd, M.A. Apicella, M.P. Jennings, A.G. McEwan, Defenses against oxidative stress in Neisseria gonorrhoeae: a system tailored for a challenging environment, Microbiol. Mol. Biol. Rev. 70 (2006) 344-361.

[2] H.J. Wu, K.L. Seib, J.L. Edwards, M.A. Apicella, A.G. McEwan, M.P. Jennings, Azurin of pathogenic Neisseria spp. is involved in defense against hydrogen peroxide and survival within cervical epithelial cells, Infect. Immun. 73 (2005) 8444-8448.

[3] J.M. Atack, D.J. Kelly, Structure, mechanism and physiological roles of bacterial cytochrome c peroxidases, Adv. Microb. Physiol. 52 (2007) 73-106.

[4] G.W. Pettigrew, A. Echalier, S.R. Pauleta, Structure and mechanism in the bacterial dihaem cytochrome c peroxidases, J. Inorg. Biochem. 100 (2006) 551-567.

[5] M.P. McLaughlin, M. Retegan, E. Bill, T.M. Payne, H.S. Shafaat, S. Pena, J. Sudhamsu, A.A. Ensign, B.R. Crane, F. Neese, P.L. Holland, Azurin as a protein scaffold for a low-coordinate nonheme iron site with a small-molecule binding pocket, J. Am. Chem. Soc. 134 (2012) 19746-19757.

[6] M.E. Zaballa, L.A. Abriata, A. Donaire, A.J. Vila, Flexibility of the metal-binding region in apo-cupredoxins, Proc. Natl. Acad. Sci. U. S. A. 109 (2012) 9254-9259.

[7] A. Chaudhari, A.M. Fialho, D. Ratner, P. Gupta, C.S. Hong, S. Kahali, T. Yamada, K. Haldar, S. Murphy, W. Cho, V.S. Chauhan, T.K. Das Gupta, A.M. Chakrabarty, AzurinPlasmodium falciparum malaria and HIV/AIDS: inhibition of parasitic and viral growth by Azurin, Cell Cycle 5 (2006) 1642-1648. 
[8] E.C. Gotschlich, M.E. Seiff, Identification and gene structure of an azurin-like protein with a lipoprotein signal peptide in Neisseria-gonorrhoeae, FEMS Microbiol. Lett. 43 (1987) 253-255.

[9] J.P. Woods, J.F. Dempsey, T.H. Kawula, D.S. Barritt, J.G. Cannon, Characterization of the neisserial lipid-modified azurin bearing the H.8 epitope, Mol. Microbiol. 3 (1989) 583-591.

[10] X. Li, S. Parker, M. Deeudom, J.W. Moir, Tied down: tethering redox proteins to the outer membrane in Neisseria and other genera, Biochem. Soc. Trans. 39 (2011) 1895-1899.

[11] J.G. Cannon, Conserved lipoproteins of pathogenic Neisseria species bearing the H.8 epitope: lipid-modified azurin and H.8 outer membrane protein, Clin. Microbiol. Rev. 2 (Suppl) (1989) S1-S4.

[12] M. Deeudom, W. Huston, J.W. Moir, Lipid-modified azurin of Neisseria meningitidis is a copper protein localized on the outer membrane surface and not regulated by FNR, Antonie Van Leeuwenhoek 107 (2015) 1107-1116.

[13] F.E. Aas, X. Li, J. Edwards, M. Hongro Solbakken, M. Deeudom, A. Vik, J. Moir, M. Koomey, M. Aspholm, Cytochrome c-based domain modularity governs genuslevel diversification of electron transfer to dissimilatory nitrite reduction, Environ. Microbiol. 17 (2015) 2114-2132.

[14] K.R. Barth, V.M. Isabella, V.L. Clark, Biochemical and genomic analysis of the denitrification pathway within the genus Neisseria, Microbiology 155 (2009) 4093-4103.

[15] S. Najmudin, S.R. Pauleta, I. Moura, M.J. Romao, The 1.4 A resolution structure of Paracoccus pantotrophus pseudoazurin, Acta Crystallogr. Sect. F: Struct. Biol. Cryst. Commun. 66 (2010) 627-635

[16] E.I. Solomon, M.J. Baldwin, M.D. Lowery, Electronic-structures of active-sites in copper proteins - contributions to reactivity, Chem. Rev. 92 (1992) 521-542.

[17] W. Hashimoto, A. Ochiai, C.S. Hong, K. Murata, A.M. Chakrabarty, Structural studies on Laz, a promiscuous anticancer neisserial protein, Bioengineered 6 (2015) $141-148$.

[18] C.S. Nobrega, M. Matzapetakis, S.R. Pauleta, (1)H, (1)(3)C and (1)(5)N resonance assignment of the soluble form of the lipid-modified Azurin from Neisseria gonorrhoeae, Biomol. NMR Assign. 7 (2013) 311-314.

[19] P.M. Hanna, R. Tamilarasan, D.R. McMillin, $\mathrm{Cu}(\mathrm{I})$ analysis of blue copper proteins, Biochem. J. 256 (1988) 1001-1004.

[20] P.K. Smith, R.I. Krohn, G.T. Hermanson, A.K. Mallia, F.H. Gartner, M.D. Provenzano, E.K. Fujimoto, N.M. Goeke, B.J. Olson, D.C. Klenk, Measurement of protein using bicinchoninic acid, Anal. Biochem. 150 (1985) 76-85.

[21] E. Arslan, H. Schulz, R. Zufferey, P. Kunzler, L. Thony-Meyer, Overproduction of the Bradyrhizobium japonicum c-type cytochrome subunits of the cbb3 oxidase in Escherichia coli, Biochem. Biophys. Res. Commun. 251 (1998) 744-747.

[22] S.M. Pascal, R. Muhandiram, T. Yamazaki, J.D. Forman-Kay, L.E. Kay, Simultaneous acquisition of N-15-edited and C-13-edited NOW spectra of proteins dissolved in $\mathrm{H}_{2}$ O, J. Magn. Reson. B 103 (1994) 197-201.

[23] W. Rieping, M. Habeck, B. Bardiaux, A. Bernard, T.E. Malliavin, M. Nilges, ARIA2: automated NOE assignment and data integration in NMR structure calculation, Bioinformatics 23 (2007) 381-382.

[24] A.T. Brunger, P.D. Adams, G.M. Clore, W.L. DeLano, P. Gros, R.W. Grosse-Kunstleve, J.S. Jiang, J. Kuszewski, M. Nilges, N.S. Pannu, R.J. Read, L.M. Rice, T. Simonson, G.L. Warren, Crystallography \& NMR system: a new software suite for macromolecular structure determination, Acta Crystallogr. D Biol. Crystallogr. 54 (1998) 905-921.

[25] A.T. Brunger, Version 1.2 of the crystallography and NMR system, Nat. Protoc. 2 (2007) 2728-2733.

[26] Y. Shen, A. Bax, Protein backbone and sidechain torsion angles predicted from NMR chemical shifts using artificial neural networks, J. Biomol. NMR 56 (2013) 227-241.

[27] M. Nilges, A. Bernard, B. Bardiaux, T. Malliavin, M. Habeck, W. Rieping, Accurate NMR structures through minimization of an extended hybrid energy, Structure 16 (2008) 1305-1312.

[28] J.F. Doreleijers, A.W. Sousa da Silva, E. Krieger, S.B. Nabuurs, C.A. Spronk, T.J. Stevens, W.F. Vranken, G. Vriend, G.W. Vuister, CING: an integrated residue-based structure validation program suite, J. Biomol. NMR 54 (2012) 267-283.
[29] G.T. Hoehn, V.L. Clark, Isolation and nucleotide sequence of the gene (aniA) encoding the major anaerobically induced outer membrane protein of Neisseria gonorrhoeae, Infect. Immun. 60 (1992) 4695-4703.

[30] S. Turner, E. Reid, H. Smith, J. Cole, A novel cytochrome c peroxidase from Neisseria gonorrhoeae: a lipoprotein from a Gram-negative bacterium, Biochem. J. 373 (2003) 865-873.

[31] S.R. Pauleta, F. Guerlesquin, C.F. Goodhew, B. Devreese, J. Van Beeumen, A.S. Pereira, I. Moura, G.W. Pettigrew, Paracoccus pantotrophus pseudoazurin is an electron donor to cytochrome c peroxidase, Biochemistry 43 (2004) 11214-11225.

[32] A.A. Gewirth, E.I. Solomon, Electronic-structure of plastocyanin - excited-state spectral features, J. Am. Chem. Soc. 110 (1988) 3811-3819.

[33] E.I. Solomon, R.G. Hadt, Recent advances in understanding blue copper proteins, Coord. Chem. Rev. 255 (2011) 774-789.

[34] K.W. Penfield, R.R. Gay, R.S. Himmelwright, N.C. Eickman, V.A. Norris, H.C. Freeman, E.I. Solomon, Spectroscopic studies on plastocyanin single-crystals - a detailed electronic-structure determination of the blue copper active-site, J. Am. Chem. Soc. 103 (1981) 4382-4388.

[35] S.E. Shadle, J.E. Pennerhahn, H.J. Schugar, B. Hedman, K.O. Hodgson, E.I. Solomon, $\mathrm{X}$-ray absorption spectroscopic studies of the blue copper site - metal and ligand K-edge studies to probe the origin of the Epr hyperfine splitting in plastocyanin, J. Am. Chem. Soc. 115 (1993) 767-776.

[36] C.M. Groeneveld, M.C. Feiters, S.S. Hasnain, J. van Rijn, J. Reedijk, G.W. Canters, The $\mathrm{pH}$ and redox-state dependence of the copper site in azurin from Pseudomonas aeruginosa as studied by EXAFS, Biochim. Biophys. Acta 873 (1986) 214-227.

[37] T. Sakurai, The alkaline transition of blue copper proteins, Cucumis sativus plastocyanin and Pseudomonas aeruginosa azurin, FEBS Lett 580 (2006) 1729-1732.

[38] D. Pinho, S. Besson, C.D. Brondino, E. Pereira, B. de Castro, I. Moura, Two azurins with unusual redox and spectroscopic properties isolated from the Pseudomonas chlororaphis strains DSM 50083T and DSM 50135, J. Inorg. Biochem. 98 (2004) 276-286.

[39] E.W. Ainscough, A.G. Bingham, A.M. Brodie, W.R. Ellis, H.B. Gray, T.M. Loehr, J.E. Plowman, G.E. Norris, E.N. Baker, Spectrochemical studies on the blue copper protein azurin from Alcaligenes denitrificans, Biochemistry 26 (1987) 71-82.

[40] T. Pascher, B.G. Karlsson, M. Nordling, B.G. Malmstrom, T. Vanngard, Reduction potentials and their $\mathrm{pH}$ dependence in site-directed-mutant forms of azurin from Pseudomonas aeruginosa, Eur. J. Biochem. 212 (1993) 289-296.

[41] J. Hirst, F.A. Armstrong, Fast-scan cyclic voltammetry of protein films on pyrolytic graphite edge electrodes: characteristics of electron exchange, Anal. Chem. 70 (1998) 5062-5071.

[42] L.J.C. Jeuken, L.J. Wisson, F.A. Armstrong, The kinetics of a weakly electron-coupled proton transfer in azurin, Inorg. Chim. Acta 331 (2002) 216-223.

[43] H. Nar, A. Messerschmidt, R. Huber, M. van de Kamp, G.W. Canters, Crystal structure analysis of oxidized Pseudomonas aeruginosa azurin at pH 5.5 and $\mathrm{pH}$ 9.0. A pHinduced conformational transition involves a peptide bond flip, J. Mol. Biol. 221 (1991) 765-772.

[44] E.N. Baker, Structure of azurin from Alcaligenes denitrificans refinement at $1.8 \mathrm{~A}$ resolution and comparison of the two crystallographically independent molecules, J. Mol. Biol. 203 (1988) 1071-1095.

[45] K. Paraskevopoulos, M. Sundararajan, R. Surendran, M.A. Hough, R.R. EadyI, I.H Hillier, S.S. Hasnain, Active site structures and the redox properties of blue copper proteins: atomic resolution structure of azurin II and electronic structure calculations of azurin, plastocyanin and stellacyanin, Dalton Trans (2006) 3067-3076.

[47] B.L. Vallee, R.J. Williams, Metalloenzymes: the entatic nature of their active sites, Proc. Natl. Acad. Sci. U. S. A. 59 (1968) 498-505.

[48] L.A. Abriata, A.J. Vila, M. Dal Peraro, Molecular dynamics simulations of apocupredoxins: insights into the formation and stabilization of copper sites under entatic control, J. Biol. Inorg. Chem. 19 (2014) 565-575.

[49] J. Schilder, M. Ubbink, Formation of transient protein complexes, Curr. Opin. Struct Biol. 23 (2013) 911-918.

[50] W.G. Zumft, Cell biology and molecular basis of denitrification, Microbiol. Mol. Biol. Rev. 61 (1997) 533-616. 